\title{
The Ligation of the Intersphincteric Fistula Tract (LIFT) Technique for Simple and Complex Fistula-in-ano
}

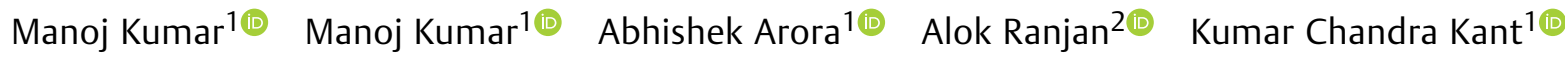 \\ Sreepriya PP1이
}

${ }^{1}$ Department of General Surgery, All India Institute of Medical

Sciences, Patna, Bihar, India

${ }^{2}$ Department of Community and Family Medicine, All India Institute

of Medical Sciences, Patna, Bihar, India

Address for correspondence Manoj Kumar, Department of General Surgery, All India Institute of Medical Sciences, Patna, Bihar, India (e-mail: drmano_mmc@yahoo.co.in).

J Coloproctol 2021;41(4):406-410.

\begin{abstract}
Keywords

- fistula-in-ano

- complex

- intersphincteric

- ligation

- recurrence

Background Fistula-in-ano is one of the most common clinical condition encountered in a surgical outpatient department. Many treatment modalities have been described with variable outcomes but gold standard surgical treatment is yet to be agreed upon. The aim of the present study is to evaluate the treatment outcomes of ligature of intersphincteric fistula tract (LIFT) technique in the treatment of simple and complex fistula-in-ano with the primary objective of recurrence rate and broad objective of other postoperative complications during the period of study and after long-term follow-up. Methods It is a retrospective study of prospectively collected data from the patients who have been operated for fistula-in-ano using the LIFT technique at our institute from February 2018 to March 2020 and followed-up until September 2020.

Results A total of 56 patients with fistula-in-ano were treated with the LIFT procedure during the study period, of which 20 patients had simple fistula and 36 had complex fistula. A success rate of $83 \%$ was obtained with completely healed fistulas in 46 patients. No patient developed postoperative incontinence.

Conclusion Ligature of intersphincteric fistula tract is an effective treatment modality for fistula-in-ano with less procedure-related morbidity, but it is associated with a higher recurrence rate in simple fistula than in complex fistula.
\end{abstract}

\section{Introduction}

Fistula-in-ano can develop in $~ 40 \%$ of patients during the acute phase of anorectal sepsis or even be discovered within 6 months of initial therapy. ${ }^{1}$

Patients usually complain of external opening in the perineum, intermittent purulent discharge (which may be bloody), and pain (which increases until temporary relief occurs when the pus discharges).

Anal fistulas are categorized by the Park classification on the basis of location relative to the anal sphincter muscles: intersphincteric, transsphincteric, suprasphincteric, or extrasphincteric. ${ }^{2}$ The most common type of anal fistula is the intersphincteric. ${ }^{1}$

Simple anal fistulas include intersphincteric and low transsphincteric fistulas that involve $<30 \%$ of the sphincter complex. The term "complex fistula" describes a fistula with any of the following: the tract crosses more than 30 to 50\% of the external sphincter, anterior fistula in a female, multiple tracts, recurrent fistula, or the patient has preexisting incontinence, irradiation, or inflammatory bowel disease. Low transsphincteric fistulas are ones where the received

November 2, 2020 accepted after revision June 15, 2021
DOI https://doi.org/ $10.1055 / \mathrm{s}-0041-1736644$ ISSN 2237-9363.

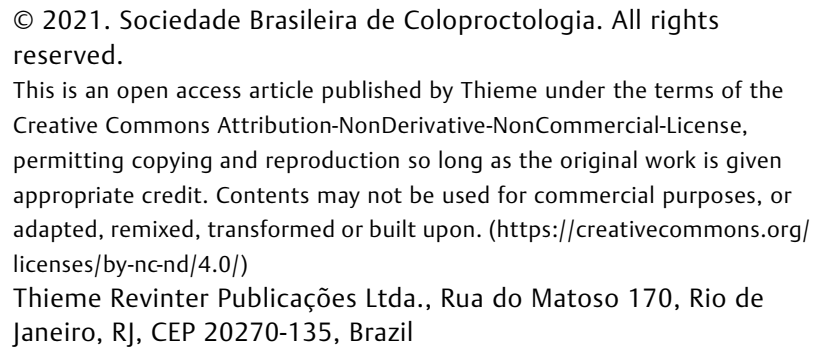

This is an open access article published by Thieme under the terms of the Creative Commons Attribution-NonDerivative-NonCommercial-License, permitting copying and reproduction so long as the original work is given appropriate credit. Contents may not be used for commercial purposes, or adapted, remixed, transformed or built upon. (https://creativecommons.org/ licenses/by-nc-nd/4.0/) Thieme Revinter Publicações Ltda., Rua do Matoso 170, Rio de Janeiro, RJ, CEP 20270-135, Brazil 
fistula tract passes through the lower third of the external anal sphincter. ${ }^{3-5}$

Rojanasakul et al., in 2007, described a novel sphinctersaving procedure, the ligation of the intersphincteric fistula tract (LIFT), and reported a success rate of $94.4 \%$ in 18 patients, without loss of continence. ${ }^{6}$ Since the introduction of LIFT, there have been many variations of the procedure, as reported by Araújo et al., with a rate of success for transsphincteric fistula-in-ano ranging from 47 to $95 \%{ }^{7}$

The main objective of the treatment in fistula-in-ano is to minimize recurrence while maintaining anal continence. Treatment options that are available for the treatment of complex fistulas include setons (draining/cutting), fistulotomy or fistulectomy (primary/staged), advancement flap, fistula plug/glue and novel techniques, which include LIFT procedure, lasers, clips, video-assisted anal fistula treatment (VAAFT), and autologous adipose-derived stem cells. $^{5,8}$

The healing rate, incontinence, and recurrence rate vary widely among the treatment options as reported in the reviewed literature. The recurrence rate for anal plugs and flap procedure is $66 \%$ and $38 \%$, respectively. ${ }^{9}$ Complex anal fistula of cryptoglandular and Crohn origin have a recurrence rate of $20 \%$ and $36 \%$ with incontinence rate of $13.2 \%$ and $9.4 \%$, respectively. ${ }^{10}$ Cutting seton in anal fistula is associated with a high incontinence rate of $12 \%{ }^{11}$

The present study reports our experience and results of the LIFT procedure for simple and complex fistula-in-ano in terms of recurrence and postprocedure complications and factors leading to recurrence of fistula.

\section{Patients and Methods}

The current study was conducted in the department of general surgery at a tertiary care institute in eastern India. A total of 56 patients were included in the study after signing the informed consent form. The study was approved by the ethical committee of the institution. Institute Research Registration No.: AIIMS/Pat/IRC/2020/465.

Study design: Case series analysis; retrospective analysis of prospectively collected data.

Study period: February 2018-September 2020.

Inclusion criteria: All patients treated with the LIFT technique for simple and complex fistula-in-ano at our institution who have completed 6 months of follow-up following treatment.

Exclusion criteria: Patients with anorectal sepsis, anorectal malignancy, incontinent patients, patients lost to followup or deceased.

The position of the external opening in the perineum was defined as anterior (anterior to transverse axis of anal verge in lithotomy position i.e., anterior to the 3 and 9 o'clock positions), posterior (posterior to the transverse axis of the anal verge in lithotomy position i.e., posterior to the 3 and 9 o'clock positions), and lateral (along the transverse axis of the anal verge in lithotomy position i.e., at the 3 and 9 o'clock positions).
All patients underwent magnetic resonance imaging (MRI) fistulograms, and fistula-in-ano were categorized according to the St. James and Park classifications. The length of the fistula on fistulogram was recorded.

Preoperative bowel preparation was done using polyethylene glycol (PEG), and all patients received preoperative intravenous antibiotics.

The external opening of the fistula and its distance from the anal verge were recorded using a disposable scale after putting the patient in prone position during the peroperative period.

The procedures were performed with the patient in the prone or Jack-knife position; the details of the technique were similar to those originally proposed in 2007 by Rojanasakul et al. ${ }^{12}$ (-Fig. 1). All the surgeries were performed by authors 1 and 2 .

Wound healing was recorded in the follow-up appointments by the operating surgeon, and recurrence and other complications were recorded. All patients received oral ciprofloxacin and metronidazole for 5 days and stool softener for 2 weeks postoperatively. Patients were instructed to take a sitz bath 2 to 3 times a day until the wound healed.

The patients were followed-up and monitored for complications, recurrence, or incontinence in the outpatient department at 1,2 , and 4 weeks after surgery, and then every 6 weeks for recurrence. Patients who were lost to follow-up were contacted by telephone. Patients unable to complete at least 2 follow-up visits were excluded from the study. In view of the ongoing pandemic, we inquired about the recurrence of fistula telephonically.

We defined fistula at follow-up as:

Healed, complete healing with the absence of an external opening and absence of symptoms within 3 months.

Unhealed or recurred, persistence of an external opening at same site or at intersphincteric groove after 3 months or

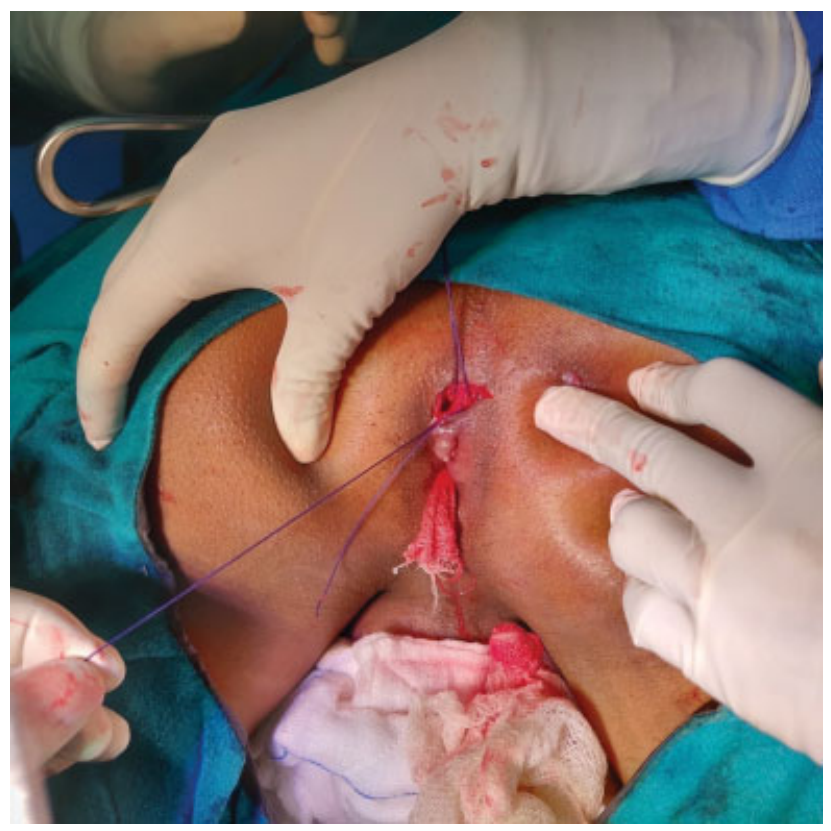

Fig. 1 Ligation of fistulous tract in the intersphincteric plane. 
recurrence of symptoms after 3 months with or without internal opening.

\section{Statistical Analysis}

Data were analyzed using the IBM SPSS Statistics for Windows, Version 26.0 (IBM Corp., Armonk, NY, USA). Continuous variables were expressed as mean (standard deviation [SD]) and median (inter-quartile range [IQR]). Categorical data were reported as percentage. Categorical variables were analyzed using the Pearson Chi-squared test $\left(\mathrm{x}^{2}\right)$ or Fisher exact test to know the significant differences between healed and unhealed fistula-in-ano.

\section{Results}

A total of 56 patients who completed 6 months of follow-up were included in the study. The mean age of the patients was 37 years, with gender distribution of 44 male and 12 female.

Of the 56 cases, 36 patients (64.3\%) had complex fistula and 20 had simple fistula (35.7\%). Thirty-two patients (57\%) had external opening in the posterior location, and discharge was the most common presenting symptom (93\%) (-Table 1).

As per the St. James classification, 26 patients (46\%) were in class IV, 42 patients (75\%) had transsphincteric fistula according to the Park classification.

Of the 56 cases, 46 patients ( $82 \%$ ) had primary fistula and 10 had recurrent fistula (18\%). Among the patients who had previous history of surgery, 4 patients (7\%) were treated with fistulotomy, 4 patients (7\%) with LIFT, and 2 (4\%) with fistulectomy.

The mean distance of external fistula from the anal verge recorded during the peroperative period was $3.62 \mathrm{~cm}$ (range $1.5-7 \mathrm{~cm}, \mathrm{SD}: 1.38$ ). The mean length of the fistula tract on imaging was $5.08 \mathrm{~cm}$ (range 2-9 cm, SD: 2.09).

The mean duration of hospital stay was 2.35 days (range 2-4, SD: 0.62) and mean duration of analgesic use were 2.29 days (range 2-3, SD: 0.46). The mean visual analogue scale (VAS) score for postoperative pain of the patient in the postoperative days (PODs) 1 and 2 were 2.1 and 1.4, respectively. The median healing time were 18 days (IQR: 17-19), and the median time to return to work was 15.5 days (IQR: 14-17).

The median duration of follow-up was 17 months with IQR 7-24 months.

Recurrence of fistula (primary outcome) was noted in 10 patients (18\%), and it occurred within 3 months following surgery for all of them. It persisted at 6 months follow-up. Among them, 8 occurred in those with simple fistula and 2 in complex fistula.

All recurrences were in patients who had primary fistula, but none in those who were operated previously. Six patients had recurrence at inter-sphincteric groove, which were successfully managed using fistulotomy; 4 had recurrence at same site, which were managed using re-LIFT.
Table 1 Symptoms and clinical presentations of patients at baseline

\begin{tabular}{|c|c|}
\hline Parameter & n (\%) \\
\hline \multicolumn{2}{|l|}{ Main symptoms } \\
\hline Discharge & $52(93 \%)$ \\
\hline Pain & $16(28 \%)$ \\
\hline Pruritus & $4(7 \%)$ \\
\hline Bleeding & $2(3 \%)$ \\
\hline \multicolumn{2}{|l|}{ Addictions } \\
\hline None & $50(89 \%)$ \\
\hline Smoking & $2(3 \%)$ \\
\hline Tobacco chewing & $4(7 \%)$ \\
\hline \multicolumn{2}{|l|}{ Comorbidities } \\
\hline None & $48(86 \%)$ \\
\hline Hypertension & $6(11 \%)$ \\
\hline Diabetes & $2(3 \%)$ \\
\hline \multicolumn{2}{|l|}{ Fistula type } \\
\hline Simple & $20(36 \%)$ \\
\hline Complex & $36(64 \%)$ \\
\hline \multicolumn{2}{|l|}{ Park classification } \\
\hline Intersphincteric & $14(25 \%)$ \\
\hline Transsphincteric & $42(75 \%)$ \\
\hline \multicolumn{2}{|c|}{ St. James classification } \\
\hline $\mathrm{I}$ & $4(7 \%)$ \\
\hline II & $10(18 \%)$ \\
\hline III & $16(29 \%)$ \\
\hline IV & $26(46 \%)$ \\
\hline \multicolumn{2}{|c|}{ Previous fistula repair } \\
\hline None & $46(82 \%)$ \\
\hline Fistulectomy & $2(4 \%)$ \\
\hline Fistulotomy & $4(7 \%)$ \\
\hline LIFT & $4(7 \%)$ \\
\hline \multicolumn{2}{|c|}{ Number of perineal opening } \\
\hline 1 & $50(89 \%)$ \\
\hline 2 & $6(11 \%)$ \\
\hline \multicolumn{2}{|c|}{ Location of external opening } \\
\hline Anterior & $18(32 \%)$ \\
\hline Posterior & $32(57 \%)$ \\
\hline Lateral & $4(7 \%)$ \\
\hline Horseshoe & $2(4 \%)$ \\
\hline
\end{tabular}

Two patients (4\%) had postoperative complication in the form of SSI, which were treated with a week-long course of oral antibiotics. None of the patients had postoperative incontinence.

Analysis of factors that lead to the recurrence of fistula is listed in -Table 2. 
Table 2 Analysis of factors associated with recurrence of fistula

\begin{tabular}{|l|l|l|l|}
\hline Parameters & Healed $(\boldsymbol{n}=\mathbf{4 6})$ & Unhealed $(\boldsymbol{n}=10)$ & $\begin{array}{l}\text { Significance } \\
(\boldsymbol{p} \text {-value })\end{array}$ \\
\hline 1. Simple vs complex & $\begin{array}{l}\text { Simple }(12 / 46=26.1 \%) \\
\text { Complex }(34 / 46=73.9 \%)\end{array}$ & $\begin{array}{l}\text { Simple }(8 / 10=80 \%) \\
\text { Complex }(2 / 10=20 \%)\end{array}$ & 0.001 \\
\hline $\begin{array}{l}\text { 2. Distance of External opening } \\
\text { from anal verge }(<3 \mathrm{~cm} \text { vs } \geq 3 \mathrm{~cm})\end{array}$ & $\begin{array}{l}<\mathrm{cm}(8 / 46=17.4 \%) \\
\geq 3 \mathrm{~cm}(38 / 46=82.6 \%)\end{array}$ & $\begin{array}{l}<3 \mathrm{~cm}(6 / 10=60 \%) \\
\geq 3 \mathrm{~cm}(4 / 10=40 \%)\end{array}$ & 0.005 \\
\hline 3. Park's classification & $\begin{array}{l}\text { Intersphincteric }(8 / 46=17.4 \%) \\
\text { Transsphincteric }(38 / 46=82.6 \%)\end{array}$ & $\begin{array}{l}\text { Intersphincteric }(6 / 10=60 \%) \\
\text { Transsphincteric }(4 / 10=40 \%)\end{array}$ & 0.037 \\
\hline 4. No. of external openings & $\begin{array}{l}1(40 / 46=87 \%) \\
2(6 / 46=13 \%)\end{array}$ & $\begin{array}{l}1(10 / 10=100 \%) \\
2(0 / 10=0 \%)\end{array}$ & 0.227 \\
\hline 5. Primary vs recurrent fistula & $\begin{array}{l}\text { Primary }(36 / 46=78.3 \%) \\
\text { Recurrent }(10 / 46=21.7 \%)\end{array}$ & $\begin{array}{l}\text { Primary }(10 / 10=100 \%) \\
\text { Recurrent }(0 / 10=0 \%)\end{array}$ & 0.104 \\
\hline
\end{tabular}

\section{Discussion}

The primary objective of our study was to assess the recurrence rate after the LIFT procedure for fistula-in-ano. We found a recurrence rate of $18 \%$, with most recurrences occurring within 3 months of surgery, in the intersphincteric groove and in patients with a simple fistula.

In a 6-year follow-up of 251 patients who underwent LIFT procedure, recurrence rate was found to be $13 \%$ for anal fistula. ${ }^{13}$ In a clinical trial comparing LIFT with mucosal advancement flap for the treatment of high transsphincteric anal fistulas, recurrence rates of $26 \%$ and $35 \%$ in LIFT and mucosal advancement flap, respectively, were observed at 1 year of follow-up. ${ }^{14}$

In other studies, Abcarian et al. reported a healing rate of $90 \%$ in patients who underwent LIFT as a primary procedure in comparison to $65 \%$ in patients who had $\geq 2$ operations before LIFT. $^{15}$

In a study by Liu et al., patients with transsphincteric fistula-in-ano treated with LIFT had an overall primary healing rate of $61 \%$, which persisted at 12 months followup. Most of the failures were early failures, which authors defined as persistent symptoms or failure at $\leq 6$ months. The authors also reported that decrease in the healing rate was associated with increase in the length of the fistula tract. ${ }^{16}$

Bleier et al. found that patients with complex transsphincteric fistulas who had previous failed repair when treated with ligation of the intersphincteric fistula tract had a success rate which is comparable with other sphincterpreserving techniques without any subjective decrease in continence after the procedure. The fistula closure rate reported by the authors was $57 \%$ for complex fistula. ${ }^{17}$

The primary healing and recurrence rate were $82.2 \%$ and $17.7 \%$, respectively, when complex or transsphincteric fistula-in-ano and were treated with the LIFT technique plus coring out of the external tract, as reported by Shanwani et al. Moreover, this procedure was not associated with loss of continence. ${ }^{18}$

Kontovounisios et al. systemically reviewed the results of LIFT showing that the success rate ranged from 51 to $94 \%$, and it has remained constant with time, though the adoption rate has increased. ${ }^{19}$
Sun et al. reported healing rate for high transsphincteric fistula-in-ano for mature and immature fistulas were $83.7 \%$ and $77.3 \%$, respectively, with negligible impairment on continence on long term. ${ }^{20}$

On analyzing the factors which affect healing of the fistula tract, we found that simple fistulas, fistulas with external opening within $3 \mathrm{~cm}$, and intersphincteric fistulas were significantly associated with recurrence of fistula following LIFT ( - Table 2). This can be explained on the basis of failure of ligation and identification of tract, immature tract, slippage of ligature and cases done early in our learning curve. The length of the simple fistulas that we found in our study varied from 2 to $2.5 \mathrm{~cm}$. These smaller tracts could be the cause of recurrence, because ligating these tracts in the intersphincteric groove may be a challenging task. Sun X-L et al. have also reported that the small size of the intersphincteric tract may also increase the risk of a technical error. ${ }^{20}$ We could conclude that simple fistulas can be managed with fistulotomy rather than LIFT, but that might be oversimplification considering the sample size of our study.

Recurrences in complex fistulas that occurred following LIFT were located in the intersphincteric groove, thus turning complex fistula into simple fistula, which could be managed well with fistulotomy without affecting sphincter function.

\section{Conclusion}

Recurrence rate in simple fistula is comparatively higher than in complex fistula when treated with the LIFT technique. The LIFT technique is an excellent sphincter-saving option for complex fistula-in-ano with no postoperative incontinence.

Funding

This research did not receive any specific grant from funding agencies in the public, commercial, or not-forprofit sectors.

Conflict of Interests

The authors declare that they have no conflict of interests. 


\section{References}

1 Townsend C Jr., Beauchamp R, Evers B. Sabiston textbook of surgery. 20th ed. Saunders Elsevier; 2017:1406-1409

2 Parks AG, Gordon PH, Hardcastle JD. A classification of fistula-inano. Br J Surg 1976;63(01):1-12

3 van Onkelen RS, Gosselink MP, van Rosmalen J, Thijsse S, Schouten WR. Different characteristics of high and low transsphincteric fistulae. Colorectal Dis 2014;16(06):471-475

4 Steele SR, Kumar R, Feingold DL, Rafferty JL, Buie WDStandards Practice Task Force of the American Society of Colon and Rectal Surgeons. Practice parameters for the management of perianal abscess and fistula-in-ano. Dis Colon Rectum 2011;54(12):1465-1474

5 Bubbers EJ, Cologne KG. Management of Complex Anal Fistulas. Clin Colon Rectal Surg 2016;29(01):43-49

6 Rojanasakul A, Pattanaarun J, Sahakitrungruang C, Tantiphlachiva K. Total anal sphincter saving technique for fistula-in-ano; the ligation of intersphincteric fistula tract. J Med Assoc Thai 2007;90 (03):581-586

7 Araújo SEA, Marcante MT, Mendes CRS, et al. INTERESFINCTERIAL LIGATION OF FISTULA TRACT (LIFT) FOR PATIENTS WITH ANAL FISTULAS: A BRAZILIAN BI-INSTITUTIONAL EXPERIENCE. Arq Bras Cir Dig 2017;30(04):235-238

8 Williams G, Williams A, Tozer P, et al. The treatment of anal fistula: second ACPGBI Position Statement - 2018. Colorectal Dis 2018;20(Suppl 3):5-31

9 Wang JY, Garcia-Aguilar J, Sternberg JA, Abel ME, Varma MG. Treatment of transsphincteric anal fistulas: are fistula plugs an acceptable alternative? Dis Colon Rectum 2009;52(04): 692-697

10 Soltani A, Kaiser AM. Endorectal advancement flap for cryptoglandular or Crohn's fistula-in-ano. Dis Colon Rectum 2010;53 (04):486-495
11 Ritchie RD, Sackier JM, Hodde JP. Incontinence rates after cutting seton treatment for anal fistula. Colorectal Dis 2009;11(06):564-571

12 Rojanasakul A. LIFT procedure: a simplified technique for fistulain-ano. Tech Coloproctol 2009;13(03):237-240

13 Malakorn S, Sammour T, Khomvilai S, et al. Ligation of Intersphincteric Fistula Tract for Fistula in Ano: Lessons Learned From a Decade of Experience. Dis Colon Rectum 2017;60(10):1065-1070

14 Madbouly KM, El Shazly W, Abbas KS, Hussein AM. Ligation of intersphincteric fistula tract versus mucosal advancement flap in patients with high transsphincteric fistula-in-ano: a prospective randomized trial. Dis Colon Rectum 2014;57(10): 1202-1208

15 Abcarian AM, Estrada JJ, Park J, et al. Ligation of intersphincteric fistula tract: early results of a pilot study. Dis Colon Rectum 2012; 55(07):778-782

16 Liu WY, Aboulian A, Kaji AH, Kumar RR. Long-term results of ligation of intersphincteric fistula tract (LIFT) for fistula-in-ano. Dis Colon Rectum 2013;56(03):343-347

17 Bleier JIS, Moloo H, Goldberg SM. Ligation of the intersphincteric fistula tract: an effective new technique for complex fistulas. Dis Colon Rectum 2010;53(01):43-46

18 Shanwani A, Nor AM, Amri N. Ligation of the intersphincteric fistula tract (LIFT): a sphincter-saving technique for fistula-inano. Dis Colon Rectum 2010;53(01):39-42

19 Kontovounisios C, Tekkis P, Tan E, Rasheed S, Darzi A, Wexner SD. Adoption and success rates of perineal procedures for fistula-in-ano: a systematic review. Colorectal Dis 2016;18 (05):441-458

20 Sun X-L, Wen K, Chen Y-H, Xu Z-Z, Wang X-P. Long-term outcomes and quality of life following ligation of the intersphincteric fistula tract for high transsphincteric fistulas. Colorectal Dis 2019;21 (01):30-37 